\title{
A LEITURA NO BRASIL COLÔNIA E SUAS (INTER)RELAÇÕES COM A CONTEMPORANEIDADE
}

\author{
Gustavo Borges de Sousa ${ }^{1}$ \\ Luciana Beatriz de Oliveira Bar de Carvalho ${ }^{2}$ \\ Carlos Henrique de Carvalho ${ }^{3}$
}

\begin{abstract}
Resumo
O entendimento da leitura e da produção de livros no Brasil pode ser visto como um processo de construção social a partir do modo de colonização arbitrado pela metrópole portuguesa. Diante disso, a formação intelectiva do brasileiro teve perdas, uma vez que lhe foi impedido o acesso a construções ideológicas importantes e ganhos, porque teve que driblar as peias coercitivas impostas pela pátria lusitana. Pero Vaz de Caminha, Gregório de Matos, Tomás Antônio Gonzaga foram alguns dos nomes que conseguiram na contemporaneidade a valorização justa em função não só da qualidade textual de suas obras, mas do esforço em serem escritores em um país de poucos leitores e, principalmente, incentivos ligados à intelectualidade. Neste sentido, percebe-se a colonização do país não só como exploratória, mas também como inibidora do processo emancipatório do brasileiro. O reflexo disso, na literatura atual, é a reprodução de situações que marcam a construção sócio-histórica do país desde sua base colonial. Portanto, para compreender o hoje, faz-se necessário revisitar o ontem.
\end{abstract}

Palavras-chave: Literatura colonial. História do livro. História da leitura.

\section{THE READING IN COLOMBIA BRAZIL AND ITS (INTER) RELATIONS WITH CONTEMPORARY}

\begin{abstract}
The understanding of reading and book production in Brazil can be seen as a process of social construction based on the mode of colonization arbitrated by the Portuguese metropolis. Given this, the intellectual formation of the Brazilian suffered losses, once he was denied access to important ideological constructions and gains, because he had to overcome the coercive cases imposed by the Lusitanian homeland. But Vaz de Caminha, Gregorio de Matos, Tomás Antonio Gonzaga were some of the names that have achieved in the contemporary times the fair value due not only to the textual quality of their works but to the effort to be writers in a country with few readers, incentives linked to the intelligentsia. In this sense, one can perceive colonization of the country not only as exploratory, but also as an inhibitor of the Brazilian emancipatory process. The reflection of this, in the current literature, is the reproduction of situations that mark the socio-historical construction of the country from its colonial base. Therefore, to understand today, it is necessary to revisit yesterday.
\end{abstract}


Keywords: Colonial literature. History of the book. History of reading.

\title{
LA LECTURA EN BRASIL COLONIA Y SUS (INTER) RELACIONES CON LA CONTEMPORANEIDAD
}

\begin{abstract}
Resumen
Comprensión de la lectura y la producción de libros en Brasil puede verse como un proceso de construcción social de la liquidación de modo arbitrado por la metrópoli portuguesa. En este sentido, la formación intelectiva del brasileño tuvo pérdidas, una vez que se le impidió el acceso a construcciones ideológicas importantes y ganas, porque tuvo que driblar las peas coercitivas impuestas por la patria lusitana. Y en el sentido de que no se trata de una obra de arte, sino de un esfuerzo por ser escritores en un país de pocos lectores y, sobre todo, incentivos vinculados a la intelectualidad. En este sentido, se percibe colonización del país no sólo como exploratoria, sino también como inhibidora del proceso emancipatorio del brasileño. El reflejo de ello, en la literatura actual, es la reproducción de situaciones que marcan la construcción socio histórica del país desde su base colonial. Por lo tanto, para comprender el hoy, es necesario revisar el ayer.
\end{abstract}

Palabras clave: Literatura colonial. Historia del libro. Historia de la lectura.

Para entender a leitura no Brasil colônia, é preciso compreender a formação do Estado brasileiro como fruto das confluências de interesses estrangeiros. Uma das correntes históricas que contribuíram para tal formação é o Renascimento, marco da modernidade. Laurence Hallewell, estudioso da História do "Livro no Brasil", afirma que o fim da idade média se deu com "Achegada de Vasco da Gama à calecute, em 17 de abril de 1498, uma nova porção de 'Índias' fora revelada no Ocidente pelo desembarque de Cristóvão Colombo na ilha Watling (ou seja lá onde tenha sido), em 12 de outubro de 1492." (HALLEWELL, 2012, p. 34).

Tal época acreditava que os valores construídos por vias antropomórficas seriam suficientes para conduzir o homem à felicidade prometida pelo período anterior. Em outras palavras, os domínios da razão e das técnicas matemáticas sinalizariam a coordenação da vida pelo homem, algo suficientemente audacioso em um momento de agonia medieval. René Descartes, filósofo europeu moderno, explica a nova era por meio de uma analogia da área da engenharia, segmento por si só dependente da racionalidade e exatidão matemática: "Assim, vemos que os edifícios que um só arquiteto iniciou e concluiu costumam ser mais belos e bem-ordenados do que os que muitos tentaram reformar. Valendo-se das velhas paredes construídas para outros fins." (DESCARTES, 2008, p. 21). 
Os edifícios criados por um só arquiteto teriam um só estilo, uma só coerência e uma só ordenação. Não estariam sujeitos a diversas teorias, enfim seriam racionalmente construídos e não influenciados por metafísica alguma.

Diante deste escrúpulo de exatidão, explicação comprobatória e cálculos, o Brasil foi invadido em, de acordo com a história convencionada, 1500, por tropas portuguesas. Iniciase então o processo de verificação da terra, catalogação, codificação e informação a Portugal, que decidiria a forma de colonização que mais atendesse seus interesses.

Em relação ao processo editorial que poderia começar a ser feito no país, uma vez que já havia tal processo em colônias lusitanas na Índia e em Portugal, a metrópole sancionou a lei conhecida como Concílio de Latrão, 1512, no qual as impressoras da Europa deveriam submeter seus textos à aprovação litúrgica.

Esta situação coercitiva na produção textual e consecutivamente na intelecção do país recém-formado era um modo político de manter a centralização do poder, algo muito comum em administrações conservadoras, oriundas do modelo denominado "monarquia absolutista". Em tal forma de administração do estado, o patriarcalismo impera e se mostra como hierárquico em todas as estruturas. Havia, portanto, um certo receio por parte de Portugal em dar oportunidade de emancipação intelectual aos habitantes da pátria além-mar. É, no entanto, reconhecível o trauma em função da revolução contrária ao poder instituído proposto por Johann Guttemberg ao criar a prensa e promover um avanço na produção de obras, surgimento da imprensa e circulação de ideias. A revolução tecnológica foi tal que as prensas medievais substituíram as peças de madeira para a utilização de tipos móveis feitos a partir de chumbo derretido, o que refletiu na queda dos custos finais, uma vez que as peças poderiam ser realocadas e reutilizadas em outras impressões. Isso foi o estopim para que intelectuais renomados tivessem suas ideias ultrapassando barreiras geográficas, temporais e culturais. De acordo com EL FAR (2006, p. 10),

Graças ao invento do tipógrafo alemão, o texto impresso deixou de ser um privilégio de poucos, ganhando com isso usos e repercussões bastante variadas por exemplo, o jornal diário, os panfletos de divulgação e, em especial, a disseminação em massa de inúmeros gêneros literários.

Isso tudo quer dizer que os administradores europeus, ou seja, os fundadores da era moderna, já sabiam que o livro e a leitura seriam instrumentos democráticos que, portanto, caminhariam na contramão dos valores instituídos até então e aumentariam o custo administrativo uma vez que escolas deveriam ser criadas a fim de preparar o público leitor para o objeto livro. Essa situação pressiona a corte portuguesa internamente e ou outros países que se desenvolviam a passos largos também exerciam uma pressão aos lusitanos: desenvolver ou não desenvolver? Eis a questão. A dicotomia está na forma administrativa que não possibilitava a discussão de valores tradicionais instituídos, daí a opção por deixar 
o Brasil à margem do processo editorial e também no medo da superação por nações inimigas como França, Inglaterra e Espanha, por exemplo. Então, segundo a estudiosa da Unicamp,

Diferentemente do governo espanhol, que autorizava a abertura de estabelecimentos gráficos em suas colônias na América, a metrópole portuguesa, até a vinda da família real, em 1808, proibiu expressamente qualquer tipo de reprodução impressa em todo o território nacional por temer a possível propagação de ideias políticas progressivas e revolucionárias. (EL FAR, 2006, p. 12).

No tocante especificamente ao Brasil, a história nos remete à esquadra portuguesa, já dotada de uma vasta experiência, que remava às Índias. A Obsessão pelo mar é tão notória que Fernando Pessoa, no século XX, cunharia os portugueses de argonautas no célebre poema "navegar é preciso, viver não é preciso". O poeta anuncia a ambiguidade na navegação em épocas de exatidão matemática: navegar é preciso, no sentido de necessidade e também no sentido de precisão, exatidão. Viver não é preciso, isto é, abre-se mão da vida ou de algo que é inconstante, instável, impreciso.

Ainda neste processo de relevância marítima, Portugal nos apresenta Pedro Álvares Cabral, um funcionário da corte a qual, por sua vez, não possuía interesse, pelo menos nos primeiros anos de colonização, em educação, cultura e literatura. A intenção lusitana era vigiar a costa brasileira contra a invasão francesa e criar expedições para o reconhecimento da nova terra que, provavelmente, devolveria aos cofres do estado português o investimento gasto com tal empresa. Essa ideologia mercantil está bem sinalizada no texto considerado a certidão de nascimento do Brasil, uma vez que foi o primeiro gênero textual produzido em terras americanas: "A Carta Achamento do Brasil" de autoria de Pero Vaz de Caminha. Nela, além da descrição da nova terra, dos ares, dos costumes indígenas, há também preocupação mercantil:

\footnotetext{
Viu um deles umas contas de rosário, brancas; acenou que lhas dessem, folgou muito com elas, e lançou-as ao pescoço. Depois tirou-as e enrolou-as no braço e acenava para a terra e de novo para as contas e para o colar do Capitão, como dizendo que dariam ouro por aquilo.Isto tomávamos nós assim por assim o desejarmos. Mas se ele queria dizer que levaria as contas e mais o colar, isto não o queríamos nós entender, porque não lho havíamos de dar. E depois tornou as contas a quem lhas dera. (MOISÉS, 2002, p. 16).
}

Caminha deixa bem claro os interesses de Portugal ao traduzir os gestos indígenas em referência ligadas ao ouro. No entanto. O primeiro produto a seduzir o português, o famigerado Pau-Brasil, foi extraído mediante autorização da coroa e retratado muito bem na nota de dez reais, publicada em 2000 em homenagem aos 500 anos do Brasil: 


\section{Revista HIIS'TNIDBR (On-line}

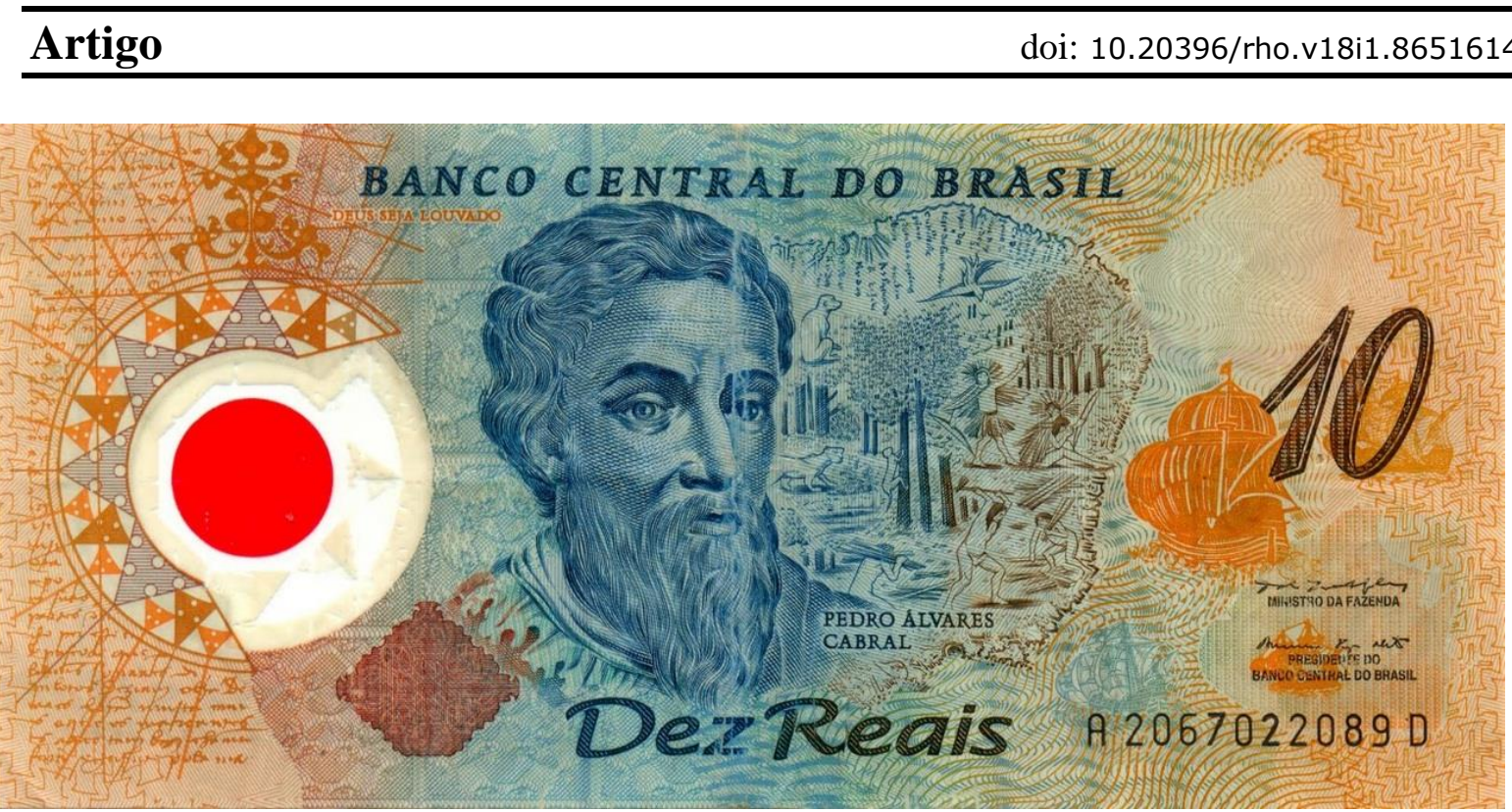

Imagem 1 - Nota Cédula dos 500 anos de Brasil

Fonte: GOSSEN, 2018.

Além desse papel-moeda comemorativo, o pau-brasil também gerou uma coletânea proposta por Oswald de Andrade, intitulada "Poesia Pau-Brasil". Trata-se de um conjunto de textos destinados a fazer apologia ao Brasil propagado pelos modernistas. O nome faz referência ao primeiro produto "tipo exportação" capaz de seduzir o europeu. Por extensão, a propagação dos valores brasileiros faria, a partir do século $\mathrm{XX}$, a antropofagia cultural da Europa, isto é, a colonização executada tendo o Brasil como pólo dominante.

É importe ressaltar, na nota comemorativa, que o trabalho dos índios, ao fundo da imagem, não foi solitário, pois vieram também para o país alguns exilados de Portugal, em função de algum crime cometido contra a lusitana pátria; marinheiros desertores, que se negaram a voltar a sua nação e absorveram os costumes da nova terra e também os náufragos. O mesmo Oswald de Andrade retrata, no poema Brasil, o encontro étnico como uma grande colaboração festiva:

O Zé Pereira chegou de caravela

E preguntou pro guarani da mata virgem

- Sois cristão?

- Não. Sou bravo, sou forte, sou filho da Morte

Teterê tetê Quizá Quizá Quecê!

Lá longe a onça resmungava Uu! ua! uu!

O negro zonzo saído da fornalha

Tomou a palavra e respondeu:

- Sim pela graça de Deus

Canhem Babá Canhem Babá Cum Cum!

E fizeram o Carnaval. (ANDRADE, 1974, p. 169-170).

Entende-se aqui Carnaval não como o feriado agraciado pela maioria dos brasileiros, mas como uma dança sociológica da confraternização universal, como o fato social da integração das etnias e do respeito entre todos, concepção muito diversa do espírito 
Quinhentista governado pelos portugueses-católicos da época. O desinteresse educacional na colônia foi acentuado a partir do projeto político da divisão das terras em capitanias hereditárias. Os capitães-donatários recebiam um comunicado oficial via carta e tomavam posse administrativa da propriedade territorial, mas os lucros continuavam direcionados ao outro lado do atlântico. É o que se afirma em: “[...] o rei delimitou as vantagens da colonização reservando para si o dízimo das colheitas, pescados e do monopólio do paubrasil, das especiarias das drogas, o quinto das pedras e metais preciosos." (MOTA, 2002, p. 200).

A partir de 1527, com o declínio do comércio com as Índias, Portugal decide enviar colonos para morar e implantar o modo de vida colonial, como bem explicitado no filme "Desmundo", que se vale do prefixo "DES" justamente para sinalizar algo que ainda não se formou, caótico, desconjuntado. Assim, cargos administrativos foram criados com a intenção de se vistoriar organizar a extração do pau-brasil e, por sua vez, garantir a lucratividade da metrópole.

A geografia da colônia, então foi dividida em dois pólos de organização: Salvador e Rio de Janeiro. A capital da Bahia, em primeiro plano, relaciona-se a nomes como Gregório de Matos de Padre Vieira, figuras capitais na literatura do Brasil na época dos seiscentos. Já Rio de Janeiro se explica por ser uma cidade cujo porto ficava mais próxima da zona econômica Vila Rica, atual Outro Preto. Culturalmente, esta foi representativa da escrita de qualidade no Brasil colônia e possuidora de autores de Best-Sellers, como Tomás Antônio Gonzaga e Cláudio Manoel da Costa.

Na época do Quinhentismo Brasileiro, Padre José de Anchieta, funcionário da companhia de Jesus. O missionário possuía um projeto educacional ligado à moral cristã e seus textos evangelizadores como autos e poesias tiveram eficácia no processo de expansão da fé e no abrandamento dos instintos de colonos rebeldes. Seus ecos, no entanto, foram calados no século XVIII quando o Marquês de Pombal, administrador no governo de Dom José, resolveu aplicar políticas racionais oriundas do iluminismo francês e então expulsou os jesuítas da colônia, proibiu o ensino religioso e substituiu nomes tupis de cidades por nomes religiosos. A ação de Pombal foi a primeira, com expressividade e respaldo político, literalmente antipedagógica, porém sinalizadora da intenção do português durante séculos: usurpar o país mediante a exploração das riquezas e a alienação de um povo.

Este panorama administrativo proposto pelo ministro de Dom José, no entanto, se sustentará somente até a Revolução do Porto, de caráter liberal. Segundo, HALLEWELL,

Em 1754, Pombal baniu toda a impressão colonial, mas, como no Brasil ainda não tinha prelo, essa proibição afetava diretamente possessões orientais de Portugal. Suas ideias foram difundidas entre os pensadores progressistas: a Flauta Mágica, de Mozart, por exemplo, é um ataque quase contemporâneo ao obscurantismo dos jesuítas. Assim, após ter expulsado a Companhia de Jesus, em 1759, de todos os 
territórios portugueses, Pombal logrou convencer as outras potências católicas, e no fim o próprio Vaticano, a fazer o mesmo. (HALLEWELL, 2012, p. 54).

Nesta época, século XVIII, a centralização do poder era tão significativa que o escritor brasileiro confeccionava seu texto na américa, enviava o material à navio, para Coimbra ou Lisboa, aguardava a impressão e o transporte de volta, arcava com taxas de importação elevadíssimas e só assim, cerca de 1 ano depois estaria com o texto em mãos. É o que demonstra EL FAR:

Assim, durante o período colonial, as pessoas que aqui viviam precisavam importar de Portugal os livros que desejavam, enfrentando, com isso uma série de trâmites burocráticos, os custos do transporte e a censura lusitana, primeiro concentrada nas mãos da Inquisição, depois fundamentada pelos funcionários da Real Mesa Censória, criada em 1769. (HALLEWELL, 2012, p. 12).

Mesmo diante desta dificuldade, Tomás Antônio Gonzaga, promotor de justiça em Outro Preto, conseguiu a marca de 2.000 (dois mil) exemplares de Marília de Dirceu vendidos, marca elevadíssima, inclusive, para os dias hodiernos. Este foi o primeiro Best seller que o Brasil produziu. Além dele, mais dois autores conseguiram com paciência e recursos próprios, burlar o sistema e montar pequenas bibliotecas, ambas em Minas Gerais do século XVIII. Trata-se do advogado José Pereira Ribeiro, de Mariana - MG e Luís Vieira da Silva, cônego, dono de cerca de 800 obras escritas em vários idiomas. O título de pelo menos uma delas, segundo EL FAR, pode justificar a necessidade de ser, estas bibliotecas, clandestinas: Dicionário das Heresias, erros e cismas, nome expressamente proibido em uma colônia administrada por cristãos-católicos. Obras como essas foram responsáveis pela prisão do religioso e sua extradição para Portugal. O que se temia nestes finais do século XVIII era o levante separatista que se confirmou em 1789: A Conjuração Mineira. A produção política de Tomás Antônio Gonzaga é capital para se entender este contexto, uma vez que critica a ação portuguesa em terras mineiras. Intitulada "Cartas Chilenas", o uso de pseudônimo não suficiente para impedir a retaliação das forças portuguesas, cada vez mais convencidas do perigo do livro e da leitura na colônia. Um trecho que expõe os erros portugueses, as incoerências e arbitrariedades da administração lusitana em Vila Ricam, atual Ouro Preto, está na primeira carta endereçada ao amigo Doroteu, identidade secreta de Cláudio Manoel da Costa:

Pretende, Doroteu, o nosso chefe mostrar um grande zelo nas cobranças do imenso cabedal que todo o povo, aos cofres do monarca, está devendo. Envia bons soldados às comarcas, $\mathrm{E}$ manda-lhes que cobrem, ou que metam, a quantos não pagarem, nas cadeias. (...) Entraram, nas comarcas, os soldados, e entraram a gemer os tristes povos. Uns tiram os brinquinhos das orelhas das filhas e mulheres; outros vendem as escravas, já velhas, que os criaram, por menos duas partes do seu preço. Aquele que não tem cativo, ou jóia, satisfaz com papéis, e o soldadinho estas dívidas cobra, mais violento (...) Por mais que o devedor exclama e grita que os créditos são falsos, ou que foram há muitos anos pagos, o ministro da severa cobrança a nada atende; despreza estes embargos, bem que o triste proteste de os provar incontinenti. (INFANTE, 2000, p. 410). 
A revolução em Minas proporcionou uma maior circulação de ideias e, por isso, ainda que primeiramente os textos publicados em gráfica fossem somente os oficiais, anuncia o fim da administração colonial e acelera o início à administração imperial. Antes disso, portanto, não havia casas de impressão oficiais. Os dados históricos da quantidade de prelos existentes no após século XIX possibilitam a compreensão da quantidade de casas de impressão no período anterior. Hallewell nos informa que:

Quadro 01 - Estabelecimento Comerciais e casas de Impressão, Século XIX

\begin{tabular}{|l|c|}
\hline Livrarias & 02 \\
\hline Casas de pasto (restaurante) & 17 \\
\hline Tabacarias & 18 \\
\hline Cabelereiros & 32 \\
\hline Tabernas & 216 \\
\hline
\end{tabular}

Fonte: (HALLEWELL, 2012, p.100).

O quadro acima demonstra que a preferência dos Brasileiros era a diversão e a preocupação com a leitura e o livro não era motivo de preocupação. Essa inferência encontra uma possível explicação no modo de produção na colônia, que era incompatível com a necessidade de educação e leitura. A escravidão é um modelo que força o sujeito a servir, obviamente, contra sua vontade. Neste contexto, a religião é absurdamente relevante, pois incute no indivíduo a ideia de que a resiliência é a humildade necessária para que sua alma/existência valesse a pena aos olhos do Deus católico.

Em uma sociedade predominantemente agrária, o estudo era secundário. Assim assinala Mota:

\footnotetext{
Na criação, predominava o trabalho de negros libertos, mestiços livres, de todo o tipo, e brancos pobres. Vaqueiro e peão recebiam pagamento. Entretanto, o vaqueiro se diferenciava dos demais trabalhadores, pois, após quatro ou cinco dias de serviço, em cada quatro crias, cabia-lhe uma. Assim, para formar seu próprio rebanho e formar sua fazenda. (MOTA, 2002, p. 210).
}

Esse modo de organização da pecuária brasileira também perdurou por muitos séculos. Graciliano Ramos, em sua obra Vidas Secas, anuncia com seu estilo neo-realista que o protagonista recebia, como pagamento no sertão nordestino, a quarta vaca que nascesse.

Mota (2002) é clara na ideia de que uma possível melhora no quadro social do cidadão dispensava qualquer tipo de academia. Havia, portanto, ofícios que, à moda medieval, eram passados de pai para filhos a fim de se manter o mínimo necessário à existência digna de um sujeito que não sabia o que era um Estado, mas tinha somente uma pequena ideia de um rei, longínquo, pertencente a um país, igualmente distante. 
A expedição ao sertão brasileiro necessitou da catequese como garantia da fidelidade do colono como extrator de riquezas. Note que a Educação estava sempre à reboque do projeto político-econômico lusitano e, é desta época a fundação das ordens religiosas que coordenariam os projetos escolares do Brasil da época: franciscanos, carmelitas e jesuítas, por exemplo. Segundo Mota (2002), cerca de 50 aldeias missionárias havia no Brasil daquele momento.

A estrutura social da colônia se organizava como patriarcal. Isso significa um modelo europeu calcado na concepção teocêntrica do poder em Deus no céu e no patriarca, chefe da família, na terra. A sociedade assim se organizava:

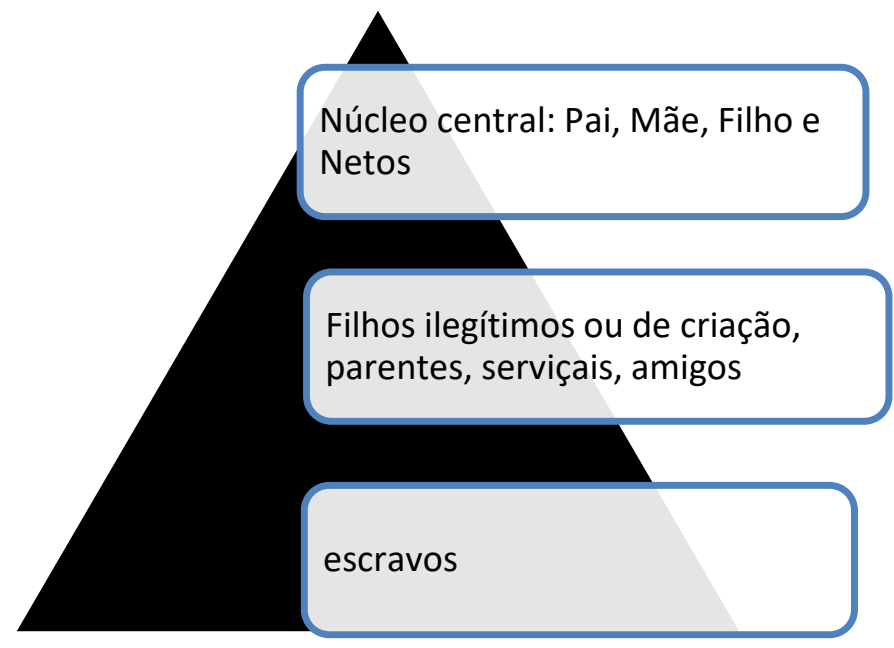

Imagem 2 - Escala Social do Brasil Colônia Fonte: (MOTA, 2002, p. 231).

$\mathrm{O}$ aprendizado dos filhos ficava restrito à classe social a que pertencia. Se o indivíduo fosse filho direto e, como se dizia na época, legítimo do dono da fazenda, tinha sua educação garantida pelo modelo da época. Eles eram enviados à Europa e voltavam bacharéis, médicos ou padres. No entanto, se fossem filhos bastardos ou de uma esfera social menos privilegiada, estariam condenados a continuar o ofício dos pais, sendo, então, vítimas daquilo que o século XIX chamaria Determinismo - corrente filosófica defendida por Hipollite Taine, que pregava que a vida estava condicionada a fatores externos com o meio, a circunstância e a hereditariedade.

Como os filhos da burguesia não podiam exercer o que se convencionou chamar de trabalho, aqueles que não possuíam título é que ocupavam os cargos necessários ao desenvolvimento das funções coloniais. Eram então, como o analfabeto Leonardinho célebre anti-herói de Memórias de um Sargento de Milícias, os desclassificados responsáveis pela guarda civil, pela fiscalização de fronteiras, pelas obras públicas e agricultura. Enquanto os modelos ociosos da elite, tão evidenciado em Dom Casmurro, de Machado de Assis, 
Artigo

doi: $10.20396 /$ rho.v18i1.8651614

ficavam circulando pela sociedade marcando a segregação social e pregando superioridade econômica, religiosa, moral e comportamental.

No tocante ao processo de editoração, não havia, segundo EL FAR, prensa na colônia. Para a estudiosa:

Diferentemente do governo espanhol, que autorizava a abertura de estabelecimentos gráficos em suas colônias na América, a metrópole portuguesa, até a vinda da família real, em 1808, proibiu expressamente qualquer tipo de reprodução impressa em todo o território nacional. (EL FAR, 2006, p. 11).

Isso significa que Portugal, já desenvolvido linguisticamente desde a expulsão dos sarracenos no século XII e já passado pela influência da prensa de Guttemberg, percebia o desastre que seria para a administração da colônia se a circulação de textos fosse frequente. Isso, faz-nos pensar sobre o poder que o exercício do livre pensamento pode materializar. Francis Bacon, famigerado filósofo da Idade Moderna, já assinalava que "Saber é Poder". Outras provas do medo do conhecimento são inevitáveis de serem citadas: a idade média proibindo o acesso aos livros do Index Librorum Proibithorum; a substituição de filosofia e sociologia por OSPB - Organização Social e Política Brasileira e EMC - Educação Moral e Cívica, no período do Regime Militar são provas de que a leitura incomoda, intimida, muitos.

O que se percebe, também, no processo de impressão do livro no Brasil Colônia é que fundamentou nesta época um privilégio de leitura concedido para integrantes da elite econômica e clerical, desde que nascidos homens. Às s mulheres, mesmo pertencentes à classe dominante, eram destinadas obras de caráter pedagógico-educativo e o país ou irmãos mais velhos, costumeiramente, impediam-nas de travar contato com livros, uma vez que o modelo comportamental patriarcal exigia uma educação para a "Economia Doméstica", nome inclusive de uma escola que ministrava aulas de etiqueta feminina, corte-costura em Uberaba-MG. O “Curso de Magistério em Economia Doméstica” funcionou até 1962. Jorge Amado, em Capitães da Areia, mostra este reflexo sócio-histórico na relação afetiva do líder protagonista, Pedro-Bala, com sua namorada, Dora:

No dia em que, vestida como um garoto, ela apareceu na frente de Pedro Bala, o menino começou a rir. Chegou a se enrolar no chão de tanto rir. Por fim conseguiu dizer:

- Tu tá gozada...

- Tu vai ver como eu vou ser igual a qualquer um...

- Tu já viu uma mulher fazer o que um homem faz? Tu não aguenta um empurrão... - Posso fazer outras coisa.

Pedro Bala se conformou. No fundo gostava da atitude dela, se bem tivesse medo dos resultados. (AMADO, 2008, p. 177).

A semelhança de Pedro-Bala, personagem ficcional do século XX e o portugueses reais do Brasil colônia está no fato de ambos temerem a emancipação feminina e a equidade social. A sociedade ideal para ambos era desnivelada e com pólo ora no homem, ora no homem rico, ora no homem rico e estudado. A diferença entre eles, no entanto, é que Pedro- 
Bala se conformou com a vontade de liberdade de Dora, mas os lusitanos não se conformaram: levaram o sistema segregacionista até o limite - 1822, sétimo dia de setembro.

$\mathrm{Na}$ esfera religiosa, as mulheres podiam ter mais acesso a textos, obviamente porque o conteúdo apreendido era integrante da forma administrativa católico-portuguesa. EL FAR (2006), então, nos ensina:

Tanto nos conventos quantos nas casas de recolhimento, que abrigavam moças solteiras, viúvas, representantes na nobreza ou mesmo de camadas menos favorecidas, a grande maioria das reclusas aprendia teologia, preces, biografias de santos, filosofia, letras, boa conduta, dentre várias outras disciplinas que acabavam por aproximá-las da experiência da leitura e da escrita. (EL FAR, 2006, p. 14).

Desta forma, percebe-se que a história do Brasil Colônia apenas tangencia o que se entende por Educação, uma vez que livro e leitura ou eram proibidos ou coordenados pela gerência metropolitana. Lia-se pouco ou às escondidas. $\mathrm{O}$ fruto desta forma de administração está arraigado, ainda que a contragosto lusitano, nas bases culturais do brasileiro e em vários momentos a literatura o recupera, o revive como se, insistentemente, o país quisesse relembrar à história de que a evolução de um povo pode ser retardada, mas nunca suprimida. Assim, percebe-se a produção da época e o esforço de ícones, como um legado a ser lido a fim de unir duas pontas de um mesmo país: o presente ao passado.

\section{REFERÊNCIAS}

ALMEIDA, M. A. de. Memórias de um sargento de milícias. 25. ed. São Paulo: Ática, 1996. (Bom Livro).

AMADO, J. Capitães da areia. Jorge Amado; posfácio Milton Hatoum. São Paulo: Companhia das Letras, 2008.

ANDRADE, O. Obras completas, VII poesias reunidas. Rio de Janeiro: Civilização Brasileira, 1974.

ASSIS, J. M. M. Memórias póstumas de Brás Cubas. São Paulo: Ática, 1975.

DESCARTES, R. Discurso do método meditações. São Paulo: Martin Claret, 2008.

EL FAR, A. O livro e a leitura no Brasil. Rio de Janeiro: Jorge Zahar, 2006.

FRESNOT, V. DESMUNDO. Direção: Adrian Cooper; Chico Andrade. Produção: Van Fresnot. Brasil: Columbia Pictures do Brasil, 2003. 1 DVD (100 min.).

GOSSEN, G. O que houve com as notas de 10 reais de plástico. Disponível em: <http://www.gurimedonho.com.br/o-que-houve-com-as-cedulas-de-10-reais-de-plastico/>. Acesso em: 01 mar. 2018. 
HALLEWELL, L. O Livro no Brasil: sua história. Trad. de Maria da Penha Villalobos, Lólio Lourenço de Oliveira e Geraldo Gerson de Souza. 3. ed. São Paulo: Ed. da USP, 2012.

INFANTE, U. Textos: leituras e escritas: literatura, língua e redação. São Paulo: Scipione, 2000. v. 1.

MOISÉS, M. A literatura brasileira através dos textos. 23. ed. São Paulo: Cultrix, 2002.

MOTA, M. B. História: das cavernas ao terceiro milênio. 2. ed. São Paulo: Moderna, 2002.

PESSOA, F. Mensagem. São Paulo: Martin Claret, 2002.

RAMOS, G. Vidas secas. 102. ed. São Paulo; Rio de Janeiro: Record, 2007.

\section{Notas}

\footnotetext{
${ }^{1}$ Mestre em Educação pela Universidade de Uberaba, Uniube. Especialista em Ensino de Literatura e Crítica Literária pela Universidade Federal do Triângulo Mineiro - UFTM. Licenciado em Letras, Português/Inglês pelas Faculdades Associadas de Uberaba - Fazu. Email: professorgustavoborges@ gmail.com

${ }^{2}$ Graduada em Pedagogia pela Universidade Federal de Uberlândia (UFU), mestre em Educação pela Universidade Federal de Uberlândia (UFU). Doutora em Educação pela Universidade Estadual de Campinas (UNICAMP). Coordenadora do Programa de Mestrado Profissional em Educação (PPGEB-UNIUBE) e Professora do Programa de Pós-Graduação em Educação (UNIUBE).

${ }^{3}$ Doutor em História pela USP, com Estágio Pós-Doutoral em História da Educação pela Universidade de Lisboa. Professor do Programa de Pós-Graduação em Educação da UFU. Bolsista Produtividade em Pesquisa do CNPq e do Programa Pesquisador Mineiro da FAPEMIG.
}

Submetido em: 04/02/2018

Aprovado em: 24/03/2018

Publicado em: 27/03/2018 